\title{
Frequency of Thyroid Dysfunctions in Euthymic Patients with Bipolar Disorder
}

\author{
Sengul Sahin ${ }^{* 1}$, Ahmet Ziya Sahin², Sakir Ozgur Keskek ${ }^{3}$ \\ ${ }^{1}$ Yuregir State Hospital, Department of Psychiatry, Adana, Turkey \\ ${ }^{2}$ Cukurova State Hospital, Department of Internal Medicine, Adana, Turkey \\ ${ }^{3}$ Health Sciences University, Department of Internal Medicine, Adana, Turkey \\ snglkcmr@hotmail.com \\ *Corresponding Author: Sengul Sahin, Yüregir State Hospital, Department of Psychiatry, Adana, Turkey.
}

Abstract

Introduction: The association between thyroid dysfunctions and mood disorders has been known for years. This study investigated the frequency of thyroid dysfunctions in euthymic patients with bipolar disorder.

Metarials and Methods:The study group consisted of 38 euthymic patients with bipolar disorder defined by Diagnostic and Statistical Manual of Mental Disorders, 5th Edition (DSM-5) criteria. Blood TSH and T4 levels were retrospectively screened in euthymic episods of the patients with bipolar disorder. This was compared with the similar studies in Turkey

Results: A total of 38 subjects (14 males, 24 females) were included the study, and their mean age was 40,47 years. Mean thyrotropin (TSH) and free T4 levels were 1,87 $\pm 1,29 \mu \mathrm{IU} / \mathrm{mL}$ and 1,19 $\pm 0,25 \mathrm{ng} / \mathrm{dL}$ respectively. TSH levels were detected outside the normal range in $15.8 \%$ of the patients.

Conclusion:These results suggest that the prevalence of high thyroid dysfunction in euthymic episod of patients with bipolar disorder and persists beyond the manic and depressive episodes.

Keywords: Bipolar disorder, thyroid dysfunctions. TSH, euthymic, mood

\section{INTRODUCTION}

Bipolar disorder (BD) is a serious, chronic mental illness with significant negative effects on the lives of patients and families. Accumulating evidence suggests that hypothalamo-pituitary-thyroid (HPT) axis dysfunction is relevant to the pathophysiology of mood disorders especially major depressive disorder. Thyroid status is predictive of treatment response in major depressive disorder and bipolar disorder (1).

The most common psychiatric symptoms associated with hypothyroidism are depression and cognitive dysfunction (2). Mania associated with hypothyroidism has been rarely reported in the literature $(3,4)$. Psychiatric symptoms in hyperthyroidism are associated with beta adrenergic receptor hyperactivity.
The relationship between mood disorders and thyroid dysfunction is not clear. Many studies have suggested thyroiditis, thyrotoxicosis or circadian rhythm disorder associations with changes in catecholamine receptor sensitivity in the central nervous system (4).

Treatment resistant depression is suggested to be associated with subclinical hypothyroidism, which may actually reduce the threshold for depression to develop(5). There are few studies on bipolar disorder and thyroid dysfunction A study showed that there is a strong link between thyroid disease and mood disorders, especially bipolar disorder (6).

The objective of this study was to establish the prevalence of thyroid dysfunctions in euthymic patients with BD. This was compared with the similar studies in Turkey (7). 
Frequency of Thyroid Dysfunctions in Euthymic Patients with Bipolar Disorder

\section{METARIALS AND METHODS}

The study design was respective. The study population records of all euthymic patients with BD who were admitted to Adana State Hospital Community Mental Health Center, Turkey, between November 2016 and May 2017. Whether or not there were any symptoms or signs of thyroid dysfunction in any of patients, thyroid function test had been done as of a routine screening in all bipolar patients once in six monthly session. The total participants consisted of euthymic patients with BD. Bipolar disorder was diagnosed by psychiatrists according to the criteria of the Diagnostic and Statistical Manual of Mental Disorders V. The thyroid hormone concentrations were measured using electro-chemiluminescence immunoassey method.

The patient exclusion criteria were as follows: aged under 18 years old or above 65 years old, substance abuse or dependence, the presence of non mental chronic medical illness, pregnancy, dementia, moderate or severe mental retardation. Patients who were receiving lithium therapy were excluded from the study because of the lithium's negative effects on thyroid functions (8). 2 patients were excluded the study because of being diagnosed hypothyroidism and on thyroxin replacement. Blood TSH and FT4 levels were retrospectively screened in euthymic episods of the patients with BD. According to mean TSH levels, the prevalence of subclinical and overt hypothyroidism/hyperthyroidism was detected. (TSH upper limit value $4.2 \mu \mathrm{g} / \mathrm{dl}$ )

Statistical analyses were performed using the SPSS 23.0 software package and the significance level used was $\mathrm{p}<0.05$. Relationships between discontinuous variables were tested by chi-square analysis. The compliance of the data with a normal distribution is analyzed via the Shapiro-Wilk test. In comparison of two independent groups, the Student's t-test was used to compare means between continuous variables, Mann Whitney U Test was used for variables that don't have normal distribution

\section{RESULTS}

This study was conducted in a Community Mental Healt Center of Adana State Hospital. In total, we enrolled 38 bipolar disorder patients (36.8\% male). The average age of these patients was 40, 47 years, desease onset age was 26,68. Sociodemographic and clinical features of patients are shown in Table 1.
Table1. Sociodemographic and clinical characteristics of patients

\begin{tabular}{|l|l|}
\hline Age & $40,47 \pm 11,54$ \\
\hline Onset age & $26,68 \pm 10,12$ \\
\hline $\begin{array}{c}\text { Sex } \\
\text { Male } \\
\text { Female }\end{array}$ & $\begin{array}{l}14(\% 36,8) \\
24(\% 63,2)\end{array}$ \\
\hline Education (years) & $7,97 \pm 8,0$ \\
\hline $\begin{array}{c}\text { Marital Status } \\
\text { Married } \\
\text { Single }\end{array}$ & $16(\% 42,1)$ \\
\hline $\begin{array}{c}\text { Smoking } \\
\text { Yes } \\
\text { No }\end{array}$ & $22(\% 57,9$ \\
\hline $\begin{array}{c}\text { Suicid attemp story } \\
\text { Yes } \\
\text { No }\end{array}$ & $18(\% 47,4)$ \\
\hline
\end{tabular}

Mean thyrotropin (TSH) and free FT4 levels (SD) were $1,87 \pm 1,29 \mu \mathrm{IU} / \mathrm{mL}$ and $1,19 \pm 0,25 \mathrm{ng} / \mathrm{dL}$, respectively. Thyroid functions were measured at normal limits in 32 patients. According to mean TSH levels, the prevalence of subclinical hypothyroidism, and subclinical hyperthyroidism was detected as $7,9 \%$ (3 subjects) and 7, 9\% (3 subjects). No overt hyperthyroidism and hypothyroidism were detected. TSH levels were detected outside the normal range in $15.8 \%$ of the patients Table 2 .

Table2. Frequency of euthyroidism, Subclinical hypothyroidism, and subclinical hyperthyroidism

\begin{tabular}{|l|l|}
\hline Euthyroidism & $32(\% 84,2)$ \\
\hline Subclinical hypothyroidism & $3(\% 7,9)$ \\
\hline Subclinical hyperthyroidism & $3(\% 7,9)$ \\
\hline
\end{tabular}

\section{Discussion}

Considering the fact that treatment resistant depression is related to subclinical hypothyroidism (9), it can be thought that bipolar mood disorder is similar related to thyroid dysfunction. Few studies have been conducted on bipolar disorder and thyroid dysfunction. It has been reported that both mixed mania and rapid-cycling bipolar disorder are highly associated with overt and subclinical thyroid abnormalities (10). We investigated the frequency of thyroid dysfunctions in euthymic patients with bipolar disorder. 
The prevalence of thyroid dysfunctions has been reported to $1.6 \%$ for overt hypothyroidism, $0.6 \%$ for overt hyperthyroidism, $2.7 \%$ for subclinical hypothyroidism, and $4.9 \%$ for subclinical hyperthyroidism in northern Turkey. In our study no overt hyperthyroidism and hypothyroidism were detected. The prevelace of subclinical hypothyroid (7.9\%), subclinical hyperthyroidism (7.9\%) and total thyroid disfunction (15.8\%) were high.

There are rare cases of manic episodes occurring in patients with hyperthyroidism(11). Patients with late-onset mania were found to have hyperthyroidism to be treated to ensure complete recovery (12). TSH levels in major depressive disorder were found to be higher than controls(13). In a large-scale study, TSH levels were found, above or below the limit value in both depressive and manic episodes of bipolar disorder(14). It is suggested that T3 augmentation accelerates treatment response in bipolar disorder depressive patients(15). In our study, we also observed that patients with bipolar disorder had a higher TSH levels than those of the general population during the remission period in the euthymic episod.

It is thought that depression is often associated with autoimmune subclinical thyroiditis, depressionmay also result from changes in the immune system, or, conversely it may be an aito immune disorder (16). Increased inflammatory biomarkers have been shown in patients with depression (17). Similiarly, inflammatory processes play a majör role in the pathophysiology of BD (18). The activation of these inflammatory pathwaysleto neuropathological conditions characterizad with depressive disorders (19) A meta-analyse confirm elevated pro inflammatory biomarkers during acute episodes of mania and/or depression among BD (20). Continued thyroid dysfunctions in BD euthymic period may also indicate that inflammatory and neuropathological pathways continue in the remission period of BD.

\section{LIMITATIONS}

Our study has some limitations, mainly due to retrospective and naturalist design. We have no data on type I and II subtypes of the bipolar disorder and rapid cycling of the patients. Additionaly, we could not detect the relationship of different subtypes of bipolar disorder to thyroid dysfunction because it would require a much larger sample. All patients were using atypical antipsychotic and/or mood stabilizer.
However, quetiapine, an atypical antipsychotic used in the treatment of bipolar disorder, was associated with a mild FT4 elevation but not TSH levels (21) and other antipsychotics, antidepressants, valproate, and carbamazepine used in treatment BD have not been reported to affect thyroid or parathyroid functions (22).

\section{ConCLUSION}

Our findings confirm that there may be a higher prevalence of thyroid dysfunction in the euthymic period in patients with bipolar disorder similar to manic and and depressive episods. Further systematic investigations based on inflammatory biomarkers and thyroid autoantibodies with thyroid hormone levels to be performed in order to confirm thyroid dysfunctionsa and the inflammatory alterations in bipolar disorder euthymic episode.

\section{REFERENCES}

[1] Bauer M,GoetzT,GlennT,WhybrowPC.Thethyroidbrain interaction in thyroid disorders and mood disorders. J Neuroendocrinol. 2008;20:1101-14.

[2] Sathya A, Radhika R, Mahadevan S, Sriram U. Mania as a presentation of primary hypothyroidism. Singapore Med J. 2009;50:65-7.

[3] Stowell CP, Barnhill JW. Acute mania in the setting of severe hypothyroidism. Psychosomatics. 2005; 46: 259-61.

[4] Haggerty JJ, Jr, Stern RA, Mason GA, Beckwith J, Morey CE, Prange AJ. Jr Subclinical hypothyroidism: A modifiable risk factor for depression? Am J Psychiatry. 1993;150:508-10.

[5] Chakrabarti S. Thyroid functions and bipolar affective disorder. J Thyroid Res 2011; 2011: 306367.

[6] Thomsen AF, Kvist TK, Andersen PK, Kessing LV. Increased risk of developing affective disorder in patients with hypothyroidism: A register-based study. Thyroid. 2005;15:700-7

[7] Kutluturk F, Yildirim B, Ozturk B, Ozyurt H, Bekar U, Sahin S, Akturk Y, Akbas A Etikan I, Cetin I.. Thyroid dysfunctions and sonographic characteristics in northern Turkey: a populationbased study. Ann Saudi Med. 2013;33(3):253-9

[8] Bocchetta A, Loviselli A. Lithium treatment and thyroid abnormalities. Clin Pract Epidemiol Ment Health. 2006;2:23 
Frequency of Thyroid Dysfunctions in Euthymic Patients with Bipolar Disorder

[9] Blum MR, Wijsman LW, Virgini VS, Bauer DC, den Elzen WP, Jukema JW Buckley BM, de Craen AJ, Kearney PM, Stott DJ, Gussekloo J, Westendorp RG, Mooijaart SP, Rodondi $\mathrm{N}$; PROSPER study group. Subclinical Thyroid Dysfunction and Depressive Symptoms among the Elderly: A Prospective Cohort Study. Neuroendocrinology. 2016;103(3-4):291-9. doi: 10.1159/000437387.

[10] Kupka RW, Luckenbaugh DA, Post RM, Leverich GS, Nolen W. Rapid and non-rapid cycling bipolar disorder: a meta-analysis of clinical studies. J Clin Psychiatry. 2003; 64(:1483-94

[11] Lee CS-N, Hutto B. Recognizing thyrotoxicosis in a patient with bipolar mania: a case report. Ann Gen Psychiatry. 2008;7

[12] Nath J, Sagar R. Late-onset bipolar disorder due to hyperthyroidism. Acta Psychiatrica Scandinavica. 2001;104(1):72-73 Thomsen AF, Kessing LV. Bipolar Disord. 2005; 7:351-7

[13] Gupta S, Mukherjee A, Biswas S, Bose S, Nath S,Nath Das H.Evaluation of Endocrine Parameters as Predictor of Major Depressive Disorder. Indian J Psychol Med. 2017; 391

[14] WysokińskiA, Kłoszewska I. Neurochem Res. 2014; 39: 1245-1253. Level of ThyroidStimulating Hormone(TSH) in Patients with Acute Schizophrenia, Unipolar Depression or Bipolar Disorder. J Affect Disord. 2018;15;229:410-414

[15] Parmentier T, Sienaert P. The use of triiodothyronine (T3) in the treatment of bipolar depression: A review of the literature.. J Affect Disord. 201815;;229:410-414
[16] Haggerty JJ Jr, Evans DL, Golden RN, Pedersen CA, Simon JS, Nemeroff CB. The presence of antithyroid antibodies in patients with affective and nonaffective psychiatric disorders. Biol Psychiatry. 1990;1;27:51-60

[17] Anisman H. Cascading effects of stressors and inflammatory immune system activation: implications for major depressive disorder. J Psychiatry Neurosci. 2009 Jan; 34:4-20.

[18] Hamdani N, Doukhan R, Kurtlucan O, Tamouza $\mathrm{R}$, Leboyer M. Immunity, inflammation, and bipolar disorder: diagnostic and therapeutic implications.

[19] Curr Psychiatry Rep. 2013; 15:387.

[20] Miller AH, Maletic V, Raison CL. Inflammation and its discontents: the role of cytokines in the pathophysiology of major depression. Biol Psychiatry 2009; 9: 732-741.

[21] Munkholm K, Braüner JV, Kessing LV, Vinberg M. Cytokines in bipolar disorder vs. healthy control subjects: A systematic review and meta-analysis. J Psychiatric Research. 2013;4:1119-1133

[22] Kelly DL, Conley R.Thyroid function in treatmentresistant schizophrenia patients treated with quetiapine, risperidone, or fluphenazine. J Clin Psychiatry. 2005; 66:80-4.

[23] Christoph U Correll, Johan Detraux, Jan De Lepeleire, Marc De Hert Effects of antipsychotics, antidepressants and mood stabilizers on risk for physical diseases in people with schizophrenia, depression and bipolar disorder. World Psychiatry. 2015; 14: 119-136.

Citation: Sengul Sahin, Ahmet Ziya Şahin, Sakir Ozgur Keskek. Frequency of Thyroid Dysfunctions in Euthymic Patients with Bipolar Disorder. Archives of Diabetes and Endocrine System. 2018; 1(2): 20-23.

Copyright: (c) 2018 Sengul Sahin, Ahmet Ziya Şahin, Sakir Ozgur Keskek. This is an open access article distributed under the Creative Commons Attribution License, which permits unrestricted use, distribution, and reproduction in any medium, provided the original work is properly cited. 